\title{
Differential Involvement of Orbitofrontal Cortex Subregions in Conditioned Cue-Induced and Cocaine-Primed Reinstatement of Cocaine Seeking in Rats
}

\author{
Rita A. Fuchs, K. Allison Evans, Macon P. Parker, and Ronald E. See \\ Department of Physiology and Neuroscience, Medical University of South Carolina, Charleston, South Carolina 29425
}

\begin{abstract}
Orbitofrontal cortex (OFC) damage elicits impulsivity and perseveration, and impairments in OFC function may underlie compulsive drug seeking in cocaine users. To test this hypothesis, we assessed the effects of fiber-sparing lesions or functional inactivation of OFC subregions on cocaine seeking in rats. Rats were trained to lever press for intravenous cocaine $(0.20 \mathrm{mg} / \mathrm{infusion}) \mathrm{paired}$ with the presentations of light plus tone stimuli. Responding was then allowed to extinguish. Rats received bilateral NMDA $(0.1 \mathrm{M})$ or sham lesions of the lateral OFC (1OFC) or medial OFC (mOFC) before self-administration training (experiment 1$)$ or muscimol plus baclofen ( 0.1 and $1.0 \mathrm{~mm}$ ) or vehicle infusions into the lOFC or mOFC before reinstatement testing (experiment 2). The effects of these manipulations on reinstatement of cocaine seeking (i.e., responding on the previously cocaine-paired lever) were assessed in the presence of the light plus tone stimuli or after a cocaine priming injection $(10 \mathrm{mg} / \mathrm{kg}$, i.p.). Post-training $10 \mathrm{FC}$ inactivation impaired conditioned cue-induced reinstatement, whereas other manipulations failed to alter this behavior. This suggests that the lOFC plays a critical role in assessing the current motivational significance of cocaine-conditioned stimuli or in using this information to guide cocaine-seeking behavior if stimulus-reward learning takes place before 10FC damage. OFC inactivation failed to alter cocaine-primed reinstatement. However, $10 \mathrm{FC}$ lesions augmented cocaine-primed reinstatement in a perseverative manner, whereas mOFC lesions attenuated cocaine-primed reinstatement, suggesting that prolonged cell loss in OFC subregions may modulate the propensity for cocaine seeking in a subregion-specific manner.
\end{abstract}

Key words: orbitofrontal cortex; cocaine; self-administration; reinstatement; conditioned stimulus; relapse

\section{Introduction}

Cocaine users continue to use cocaine despite diminished druginduced euphoria and negative consequences, including health risks, incarceration, and family problems. Cocaine-induced orbitofrontal cortex (OFC) damage appears to contribute to compulsive drug seeking and taking in cocaine users (Volkow and Fowler, 2000). Several lines of evidence support this hypothesis. First, the OFC appears to be involved in decision making and the suppression of prepotent behavior, because it becomes activated during the performance of tasks that use these cognitive functions (Nobre et al., 1999; Elliott et al., 2000; Bolla et al., 2003). Furthermore, OFC damage results in irresponsibility, impulsivity, and perseveration in humans (Bechara et al., 1994) and impairment in the ability to modify behavior after a change in reinforcement contingency in primates (Butter, 1969; Jones and Mishkin, 1972). Second, cocaine users exhibit OFC abnormalities (Volkow and Fowler, 2000). For instance, cocaine users show hypoactivity of the OFC under baseline conditions and cell loss

Received Jan. 21, 2004; revised June 7, 2004; accepted June 7, 2004

This research was supported by National Institute on Drug Abuse Grant DA10462. We thank William Berglind, J. Matthew Edwards, Jordan Case, and Ritu Mehta for their technical assistance.

Correspondence should be addressed to Dr. Rita Fuchs, Department of Physiology and Neuroscience, Medical University of South Carolina, 173 Ashley Avenue, Charleston, SC 29425. E-mail: fuchs@musc.edu.

D0I:10.1523/JNEUROSCI.1924-04.2004

Copyright $\odot 2004$ Society for Neuroscience $\quad$ 0270-6474/04/246600-11\$15.00/0 within the OFC that are proportional in severity to the extent of cocaine use (Franklin et al., 2002; Bolla et al., 2003; Matochik et al., 2003). However, cocaine users exhibit enhanced activation of the OFC in response to cocaine-associated cues (Wang et al., 1999; Bonson et al., 2002) that is, again, proportional in magnitude to the severity of craving (London et al., 2000; Volkow and Fowler, 2000). Together, these findings may reflect the increased influence of subcortical impulses after the loss of frontal cortical control (Jentsch and Taylor, 1999). Third, neuropsychological studies indicate that cocaine users exhibit deficits in executive cognitive functions ascribed to the OFC, including decision making and response inhibition, relative to drug-naive subjects (O’Malley et al., 1992; Bolla et al., 2003). Moreover, repeated cocaine administration elicits impairments in reversal learning in monkeys and rats similar to OFC lesions (Jentsch et al., 2002; Schoenbaum et al., 2003).

Collectively, this correlational evidence supports the idea that cocaine-induced OFC damage may contribute to poor judgment and compulsive drug seeking and taking in cocaine users (Volkow and Fowler, 2000). It remains unclear, however, whether OFC damage increases the propensity for drug relapse per se. To test this hypothesis, the present study investigated whether pretraining lesions or post-training pharmacological inactivation of the lateral OFC (lOFC) or medial OFC (mOFC) would facilitate cocaine seeking in a rat model of drug relapse. In 
primates, the $\mathrm{mOFC}$ is involved in monitoring the incentive value of stimuli, modifying stimulus-response-reward associations, and responding to incentive stimuli (Iversen and Mishkin, 1970; Elliott et al., 2000; Arana et al., 2003; Gottfried et al., 2003), whereas the lOFC is involved in the suppression of previously rewarded responses after a reinforcement contingency change (Iversen and Mishkin, 1970; Jones and Mishkin, 1972; Kowalska et al., 1991; Elliott et al., 2000; Arana et al., 2003). It is unclear to what extent a similar functional division exists within the rodent OFC. Nevertheless, assuming some degree of homology, we also hypothesized that impairments in mOFC function would disrupt cocaine seeking, whereas impairments in lOFC function would produce a perseverative potentiation of cocaine seeking.

\section{Materials and Methods}

Subjects. Male Sprague Dawley rats $(n=55$; Charles River Laboratories, Wilmington, MA), weighing 300-325 gm at the start of the experiment, were individually housed in a temperature- and humidity-controlled vivarium with a reversed light/dark cycle. Rats were maintained on $20-25$ gm of rat chow per day with water available ad libitum. The housing and treatment of the rats followed the guidelines of the Institute of Laboratory Animal Resources on Life Sciences Guide for the Care and Use of Laboratory Rats. Rats were given at least $5 \mathrm{~d}$ for adaptation before the start of the experiment.

Food training. Rats were trained to lever press on a fixed ratio 1 (FR1) schedule of food reinforcement (45 mg pellets; Noyes, Lancaster, $\mathrm{NH}$ ) in sound-attenuated operant conditioning chambers $(30 \times 20 \times 24 \mathrm{~cm}$; Med Associates, St. Albans, VT) during a $16 \mathrm{hr}$ overnight food training session. The chambers were equipped with two retractable levers, a stimulus light above each lever, a food pellet dispenser between the levers, a house light on the wall opposite to the levers, and a speaker connected to a tone generator (ANL-926; Med Associates). During the session, each lever press on the active lever resulted in delivery of a food pellet only. Lever presses on the inactive lever had no programmed consequences. After food training, food pellet dispensers were removed from the chambers.

Surgery. Forty-eight hours after food training, rats were anesthetized using a mixture of ketamine hydrochloride and xylazine (66 and 1.33 $\mathrm{mg} / \mathrm{kg}$, i.p., respectively) followed by equithesin $(0.5 \mathrm{ml} / \mathrm{kg}$ of a solution of $9.72 \mathrm{mg} / \mathrm{ml}$ pentobarbital sodium, $42.5 \mathrm{mg} / \mathrm{ml}$ chloral hydrate, and $21.3 \mathrm{mg} / \mathrm{ml}$ magnesium sulfate heptahydrate dissolved in $44 \%$ propylene glycol, $10 \%$ ethanol solution, i.p.). Chronic indwelling catheters were constructed using a bent-steel cannula with a screw-type connector (Plastics One, Roanoke, VA), SILASTIC tubing $(10 \mathrm{~cm}$; inner diameter, $0.64 \mathrm{~mm}$; outer diameter, $1.19 \mathrm{~mm}$; Dow Corning, Midland, MI), Marlex mesh, and cranioplastic cement, as described previously (Fuchs et al., 2002). The end of the catheter was inserted into the right jugular vein and was secured to surrounding tissue with suture. The catheter ran subcutaneously and exited on the rat's back, posterior to the shoulder blades.

Immediately after the catheter surgery, the rats were placed into a stereotaxic instrument (Stoelting, Wood Dale, IL). They received bilateral stainless-steel guide cannulas (26 gauge; Plastics One) aimed dorsal to the target brain structure using standard stereotaxic procedures [mOFC: $+4.2 \mathrm{~mm}$ anteroposterior (AP), $\pm 0.6 \mathrm{~mm}$ mediolateral (ML), $-4.3 \mathrm{~mm}$ dorsoventral (DV); lOFC: $+3.2 \mathrm{~mm} \mathrm{AP}, \pm 2.5 \mathrm{~mm} \mathrm{ML},-3.6$ $\mathrm{mm}$ DV, relative to bregma]. Three small screws and cranioplastic cement secured the guide cannulas to the skull. Stylets (Plastics One) were placed into the guide cannulas and catheter to prevent occlusion. To extend catheter patency, the catheters were flushed twice daily for $5 \mathrm{~d}$ after surgery with $0.1 \mathrm{ml}$ of an antibiotic solution of cefazolin $(10.0$ $\mathrm{mg} / \mathrm{ml}$; Schein Pharmaceutical, Florham Park, NJ) dissolved in heparinized saline (70 U/ml; Elkins-Sinn, Cherry Hill, NJ). Thereafter, catheters were flushed with $0.1 \mathrm{ml}$ of heparinized saline $(10 \mathrm{U} / \mathrm{ml})$ before each self-administration session and with $0.1 \mathrm{ml}$ of the cefazolin solution and $0.1 \mathrm{ml}$ of heparinized saline after each session. Catheter patency was periodically verified by infusing $0.08-0.10 \mathrm{ml}$ of methohexital sodium ( $20 \mathrm{mg} / \mathrm{ml}$, i.v.; SP Pharmaceuticals, Albuquerque, NM), which produces a rapid loss of muscle tone only when administered intravenously.
Self-administration. Self-administration training was conducted during $2 \mathrm{hr}$ sessions during the rats' dark cycle. Rats were trained to selfadminister cocaine on a minimum of 10 consecutive days plus additional self-administration sessions, if necessary, until they obtained $\geq 10 \mathrm{infu}-$ sions per day on 10 self-administration days and exhibited $<10 \%$ variability in responding on 3 consecutive days. Rats were trained to press a lever according to an FR1 schedule of cocaine reinforcement $(0.20 \mathrm{mg}$ of cocaine hydrochloride/ $0.05 \mathrm{ml}$ per infusion; National Institute on Drug Abuse, Research Triangle Park, NC) with a $40 \mathrm{sec}$ time-out after each infusion. The catheters were connected to liquid swivels (Instech, Plymouth Meeting, PA) via polyethylene 20 tubing that was encased in steel spring leashes (Plastics One). The swivels were suspended above the operant conditioning chamber and were connected to infusion pumps (model PHM-100; Med Associates). The house light was illuminated throughout each session. Lever presses on the active lever resulted in a 2 sec activation of the infusion pump and a 5 sec presentation of a stimulus complex, consisting of activation of the white stimulus light above the active lever and the tone generator $(78 \mathrm{~dB}, 2 \mathrm{kHz})$. After each infusion, responses on the active lever had no consequences during the time-out period. During the sessions, responses on the inactive lever had no programmed consequences but were recorded. Data collection and reinforcer delivery were controlled using Schedule Manager for Windows software version 2.09 (Med Associates).

Extinction. After the last day of drug self-administration, the rats underwent daily $2 \mathrm{hr}$ extinction sessions. The house light was illuminated throughout each session, and responses were recorded on both levers but had no programmed consequences. Rats received extinction training on a minimum of 7 consecutive days plus additional extinction sessions, if necessary, until they exhibited $\leq 25$ responses per session for 2 consecutive days (i.e., extinction criterion). This extinction criterion results in an extinction baseline that is sufficiently low to allow for the detection of a statistically significant decrease in responding relative to selfadministration and an increase in responding during conditioned cueinduced and drug-primed reinstatement testing. More stringent criteria impair stimulus-induced reinstatement by minimizing active lever responding and thereby inhibiting response-contingent stimulus presentation (R. A. Fuchs and R. E. See, unpublished observations).

Locomotor activity. To assess the general motor effects of the OFC manipulations, locomotion was measured during a $1 \mathrm{hr}$ test session. Locomotion was selected as a control measure because the effects of OFC manipulations on motivation do not influence this measure as they influence food-reinforced operant behavior. The locomotor activity test was conducted in novel Plexiglas chambers $(40.8 \times 40.8 \times 37.5 \mathrm{~cm})$ equipped with an array of eight photodetectors and corresponding light sources that emitted photobeams $8 \mathrm{~cm}$ apart and $4.5 \mathrm{~cm}$ above the chamber floor. A computerized activity system (San Diego Instruments, San Diego, CA) recorded the number of times neighboring photobeams were broken consecutively by a rat moving in the chamber.

Excitotoxic lesions and intracranial drug infusions. For intracranial infusions, the rats were held gently by the experimenters. Stainless-steel injection cannulas (33 gauge; Plastics One) were inserted to a depth of 1 ( $\mathrm{mOFC}$ ) or 2 (lOFC) $\mathrm{mm}$ below the tip of the guide cannulas. The injection cannulas were connected to $10 \mu$ l Hamilton syringes (Hamilton, Reno, NV) that were mounted on an infusion pump (Harvard Apparatus, South Natick, MA). NMDA $(0.1 \mathrm{M})$, a combination of the $\mathrm{GABA}_{\mathrm{A}}$ and $\mathrm{GABA}_{\mathrm{B}}$ agonists muscimol (Mus) and baclofen (Bac) (0.1 and 1.0 $\mathrm{mM}$, respectively), or PBS vehicle were infused bilaterally into the $\mathrm{mOFC}$ or lOFC over $2 \mathrm{~min}$ at a volume of 0.3 or $0.6 \mu \mathrm{l} /$ hemisphere, respectively. The injection cannulas were left in place for $1 \mathrm{~min}$ before and after the infusion. The dose of Mus plus Bac was selected based on previous research demonstrating that infusion of this dose of Mus plus Bac abolishes cocaine-primed reinstatement after infusion into the dorsal prefrontal cortex (McFarland and Kalivas, 2001) and abolishes conditioned cue-induced reinstatement after infusion into the nucleus accumbens core (NACcore) (Fuchs et al., 2004) in rats without altering general motor activity. The list of experimental groups and the timing of the above intracranial manipulations in experiments 1 and 2 are illustrated in Table 1.

Effects of pretraining OFC lesions on conditioned cue-induced and cocaine-primed reinstatement of cocaine-seeking behavior. In experiment 
Table 1. Pretraining and post-training intracranial manipulations

\begin{tabular}{|c|c|c|c|c|c|}
\hline Group & $n$ & Surgery & $\begin{array}{l}\text { Cue reinstatement } \\
\text { (light plus tone) }\end{array}$ & $\begin{array}{l}\text { Cocaine reinstatement } \\
\text { (10 mg/kg cocaine, i.p.) }\end{array}$ & Locomotion \\
\hline IOFC lesion & 8 & NMDA & No infusion & No infusion & No infusion \\
\hline IOFC sham & 9 & PBS & No infusion & No infusion & No infusion \\
\hline m0FC lesion & 8 & NMDA & No infusion & No infusion & No infusion \\
\hline m0FC sham & 7 & PBS & No infusion & No infusion & No infusion \\
\hline IOFC inactivation & 8 & No infusion & Mus plus $\mathrm{Bac}$ and $\mathrm{PBS}^{a}$ & Mus plus Bac and $\mathrm{PBS}^{a}$ & Mus plus Bac or PBS \\
\hline mOFC inactivation & 9 & No infusion & Mus plus $\mathrm{Bac}$ and $\mathrm{PBS}^{a}$ & Mus plus Bac and $\mathrm{PBS}^{a}$ & Mus plus Bac or PBS \\
\hline
\end{tabular}

${ }^{a}$ The order of Mus plus Bac and PBS infusions was counterbalanced across 2 test days of the same test type.

1, rats received NMDA or PBS infusions (i.e., shams) into the $1 \mathrm{OFC}$ or mOFC immediately after the stereotaxic surgery, while under anesthesia. Assignment to the lesion and sham groups was randomized. The rats were allowed to recover for $7 \mathrm{~d}$ after surgery, followed by cocaine selfadministration and extinction training as described above. Locomotor activity was assessed $22 \mathrm{hr}$ before the first reinstatement test day to examine the effects of the lesions on general activity at the approximate time of reinstatement testing. Starting on the following day, rats were tested for conditioned cue-induced and cocaine-primed reinstatement of cocaine-seeking behavior over 2 test days and received additional extinction sessions between the test days until they reached the extinction criterion. Testing for conditioned cue-induced reinstatement preceded testing for cocaine-primed reinstatement. This was done (1) to allow for the assessment of conditioned cue-induced reinstatement of cocaine seeking after an extended drug-free period and (2) to isolate the motivational effects of cocaine from the conditioned motivational effects of drug-associated stimuli (Tran-Nguyen et al., 1998; Neisewander et al., 2000; Baker et al., 2001; Fuchs et al., 2002; Alleweireldt et al., 2003; Burmeister et al., 2004).

The first reinstatement test day was designed to examine whether the lesions altered the ability of the cocaine-paired light-tone stimulus complex to reinstate responding. Rats were placed into the chambers for a 2 $\mathrm{hr}$ session during which the house light was illuminated and active lever responses resulted in $5 \mathrm{sec}$ presentations of the cocaine-paired light-tone stimulus complex in the absence of cocaine reinforcement. Each stimulus presentation was followed by a $40 \mathrm{sec}$ time-out period during which responses had no programmed consequences. Responses on the inactive lever had no programmed consequences. The second reinstatement test was designed to examine the effects of OFC lesions on the ability of a cocaine priming injection $(10 \mathrm{mg} / \mathrm{kg}$, i.p.) to reinstate responding. Immediately after the cocaine priming injection, rats were placed into the chamber for a $2 \mathrm{hr}$ session during which the house light was illuminated and responses on both levers were recorded but had no programmed consequences (i.e., no drug or stimulus presentation).

Effects of Mus plus Bac-induced functional inactivation of the OFC on expression of conditioned cue-induced and cocaine-primed reinstatement of cocaine-seeking behavior. In experiment 2 , after $7 \mathrm{~d}$ of recovery from the catheter and stereotaxic surgery, intact rats underwent cocaine selfadministration and extinction training using procedures identical to those used in experiment 1 . To examine the effects of the intracranial infusion procedure on responding, rats received sham infusions into the mOFC or lOFC before placement into the chamber on extinction day 4 . During the sham intracranial infusion procedure, rats were held gently by the experimenters. Injection cannulas were bilaterally inserted into the rats' guide cannulas and were left in place for $4 \mathrm{~min}$, but fluid was not infused through the infusion cannulas. After the rats reached the extinction criterion, they were tested for reinstatement of cocaine-seeking behavior on 4 test days (described below) and received additional extinction sessions between the test days until they reached the extinction criterion.

Using a within-subjects design, two reinstatement tests were conducted to examine the effects of OFC inactivation on the ability of the light-tone stimulus complex to reinstate responding. The testing procedures were identical to those used in the lesion experiments, except that rats received infusions of Mus plus Bac or vehicle into the mOFC or IOFC immediately before placement into the chamber. The order of Mus plus Bac versus vehicle pretreatments was counterbalanced across the 2 test days based on cocaine intake. Two additional reinstatement tests were then conducted to examine the effects of mOFC or lOFC inactivation on the ability of a cocaine priming injection $(10 \mathrm{mg} / \mathrm{kg}$, i.p.) to reinstate responding. Rats first received infusions of Mus plus Bac or vehicle into the mOFC or lOFC followed by the intraperitoneal cocaine injection. They were then placed into the chamber for a $2 \mathrm{hr}$ session during which the house light was illuminated and responses on both levers were recorded but had no programmed consequences (i.e., no drug or stimulus presentation). The order of Mus plus Bac versus vehicle pretreatments was counterbalanced across the 2 test days on the basis of cocaine intake and previous Mus plus Bac history (i.e., the order of infusions was the same as that for the conditioned cue-induced tests for half of the rats and was reversed for the other half). Seventy-two hours after the last reinstatement test day, the acute effects of Mus plus Bac and vehicle on general activity were assessed. Assignment to Mus plus Bac versus vehicle pretreatments was randomized.

Histology. Rats were transcardially perfused with PBS and 10\% formaldehyde solution. The brains were dissected out and stored in $10 \%$ formaldehyde solution until sectioning. Brains were sectioned in the coronal plane at a thickness of $75 \mu \mathrm{m}$ on a vibratome (Technical Products International, St. Louis, MO). Brain sections were mounted on gelatin-coated slides and stained for Nissl substance with cresyl violet (Kodak, Rochester, NY). The sections were examined under a light microscope. The pattern of cell loss or the most ventral point of each cannula track were mapped onto schematics of the appropriate plates from the rat brain atlas of Paxinos and Watson (1997).

Data analysis. Mixed-factor and repeated-measure ANOVAs were used to analyze responses on the active and inactive levers with lesion condition (sham, lesion) as a between-subjects factor and lever (active, inactive), day, test day (extinction, reinstatement), and time (30 min bins, 10 min bins) as within-subjects factors, where appropriate. Interaction effects were also investigated using simple main-effects tests (oneway ANOVA or $t$ test) or Tukey post hoc tests, where appropriate. Heterogeneity of variance, as indicated by Mauchly's test of sphericity, was corrected for using Greenhouse-Geisser-adjusted degrees of freedom. Unless otherwise indicated, only statistically significant effects are reported below. Time course analyses were performed for each experiment but are reported only for data sets for which time-dependent effects were observed.

\section{Results}

\section{Histology}

Photomicrographs of representative OFC lesions are included in Figure 1. Furthermore, schematics illustrating the smallest and largest lesions and the distribution of cannula placements in the rats from the lesion and inactivation experiments are included in Figures 2 and 3, respectively.

The lOFC target region was defined as an aggregate of the lateral and ventrolateral subregions of the orbitofrontal cortex based on the atlas of Paxinos and Watson (1997). Both the rodent and nonhuman primate lOFC (Walker's areas 11, 12, 13) have dense connections with known elements of the brain circuitry that mediate conditioned cue-induced and cocaine-primed reinstatement, including the dorsomedial prefrontal cortex (dmPFC), ventral tegmental area (VTA), and NACcore (Vogt 

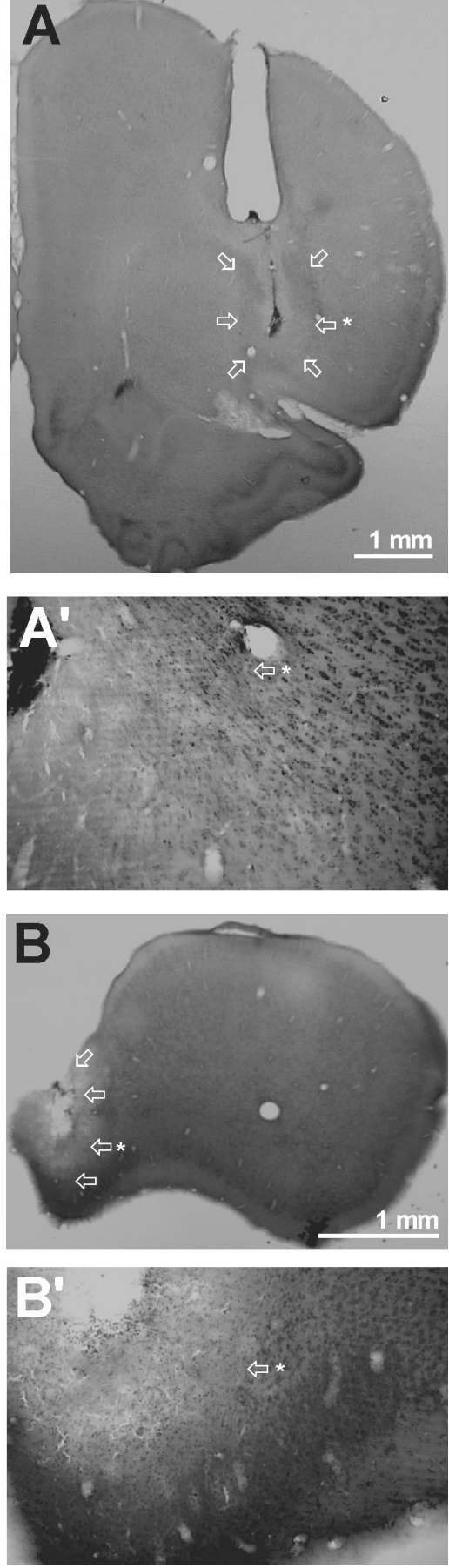

Figure 1. Photomicrographs of representative $\operatorname{IOFC}\left(A, A^{\prime}\right)$ and $\operatorname{mOFC}\left(B, B^{\prime}\right)$ lesions shown at $1 \times($ top) and $10 \times$ (bottom) magnifications. The arrows outline areas of cell loss and gliosis. The asterisk is included to serve as a reference point between pairs of photomicrographs of different magnifications.

and Pandya, 1987; Haber et al., 1995; Cavada et al., 2000; McFarland and Kalivas, 2001; Ledford et al., 2003; McLaughlin and See, 2003; Fuchs et al., 2004). In addition, the lOFC has dense reciprocal connections with the basolateral amygdala (BLA), which has been demonstrated to play a selective role in conditioned stimulus-induced reinstatement of cocaine seeking (Amaral et al., 1992; Grimm and See, 2000; McLaughlin and See, 2003). In the present study, the tracts of guide cannulas aimed at the lOFC were observed in the overlying frontal cortex, and the most ven- tral points of the tracts were bilaterally located within the lOFC. After lOFC lesions, cell loss was observed in the ventrolateral and lateral regions of the IOFC as well as in the transition area between the lOFC and the agranular insular cortex (AIC) and adjacent frontal cortex.

The mOFC target region was defined as a combination of the medial and ventromedial subregions of the orbitofrontal cortex, as indicated in the rat brain atlas of Paxinos and Watson (1997). The connectivity of the rodent mOFC has not been thoroughly investigated. The corresponding region in nonhuman primates (Walker's areas 10,14) has dense reciprocal connections with the hippocampal formation (Morecraft et al., 1992; Carmichael and Price, 1995; Cavada et al., 2000). Compared with the lOFC, the mOFC has relatively sparse connections with the dmPFC, BLA, and NACcore (Morecraft et al., 1992; Carmichael and Price, 1995; Haber et al., 1995; Cavada et al., 2000; Ongur and Price, 2000). In the present study, the tracts of guide cannulas aimed at the mOFC were observed in the overlying anterior cingulate and prelimbic ( $\mathrm{Cg} 3)$ cortices, and the most ventral points of the tracts were bilaterally located within the mOFC. After mOFC lesions, cell loss was observed bilaterally in the $\mathrm{mOFC}$ and, in three rats, in the transition area between the $\mathrm{mOFC}$ and $\mathrm{Cg} 3$.

Data obtained from rats with misplaced cannulas or with lesions in unintended brain regions were excluded from the analyses. For experiment 1, the resulting groups (sample sizes) were as follows: lOFC lesion, $n=8$; lOFC sham, $n=9$; mOFC lesion, $n=8$; mOFC sham, $n=7$. In four rats, bilateral lesions of the AIC were obtained with mild cell loss in the lateral aspect of the lOFC. These rats were grouped into a separate AIC lesion group, and their responses were compared with those of the other groups in some of the data analyses. For experiment 2, the groups (sample sizes) were as follows: 1OFC inactivation, $n=8$; mOFC inactivation, $n=9$.

\section{Pretraining lesions of the $1 \mathrm{OFC}$ or $\mathrm{mOFC}$ do not alter cocaine self-administration, extinction responding, or locomotor activity}

The effects of OFC manipulations on self-administration, extinction, and motor activity were examined because these variables can influence the magnitude of reinstatement responding (Kruzich et al., 1999). Previous research has shown that OFC lesions do not alter responding for cocaine on an FR1 schedule in rats (Hutcheson and Everitt, 2003) and responding for natural reinforcers in primates (Pears et al., 2003) but increase motor activity in Wezob rats (de Bruin et al., 1983). However, in Sprague Dawley rats, OFC manipulations did not alter any of these measures (see below). This implies that the observed OFC lesion and inactivation effects on cocaine seeking do not reflect the influence of these OFC manipulations on cocaine selfadministration, extinction, or general activity.

The effects of lOFC and mOFC lesions on self-administration and extinction are shown in Figure 4. Neither lOFC nor mOFC lesions had an effect on cocaine self-administration or extinction responding. All groups of rats quickly learned to respond for cocaine reinforcement and needed only a mean total of $10.15 \pm$ $0.07 \mathrm{~d}$ to complete the self-administration phase of the experiment. Separate overall ANOVAs for the lOFC and mOFC lesion experiments did not reveal significant lesion main or interaction effects on lever presses during the $10 \mathrm{~d}$ of self-administration. During the last 3 self-administration days, all groups of rats exhibited stable responding on the active lever, with a withinsubject variability of $<10 \%$ (range, $1.74-6.48 \%$ ). Consistent with this, separate ANOVAs for the mOFC and lOFC lesion ex- 
periments revealed only significant main effects of lever $\left(F_{(1,13)}=224.903, p<\right.$ $0.0001 ; F_{(1,15)}=301.362, p<0.0001$, respectively) on responding, indicating that the lesions did not alter the rate of responding for cocaine reinforcement and that the rats responded more on the active lever than on the inactive lever, independent of self-administration day. There was also no difference in the mean daily cocaine intake between rats in the mOFC (sham, $32.29 \pm 1.91$; lesion, $29.13 \pm 1.71$ ) versus lOFC (sham, $29.67 \pm 1.63$; lesion, $29.41 \pm 1.96)$ lesion experiments. Collapsed across these experiments, the mean \pm SEM daily cocaine intake was $30.208 \pm 0.903$ infusions $(18.426 \pm 0.607$ $\mathrm{mg} / \mathrm{kg}$ per session).

Extinction training, during which cocaine reinforcement was not available, resulted in a decrease in responding, and neither IOFC nor mOFC lesions had an effect on extinction responding. Separate ANOVAs for the 1OFC and mOFC lesion experiments indicated a significant leverby-day interaction effect $\left(F_{(6,90)}=10.787\right.$, $p<0.0001 ; F_{(6,78)}=10.852, p<0.0001$, respectively) on responding during the first 7 extinction days but did not reveal lesion main or interaction effects. Thus, active lever responding gradually declined across the extinction days independent of lesion condition. In the lOFC lesion experiment, the sham and lesion groups needed $7.55 \pm 0.38$ and $7.75 \pm 0.36 \mathrm{~d}$ on average to reach the extinction criterion, respectively. In the mOFC lesion experiment, the sham and lesion groups needed $8.14 \pm 0.46$ and $9.62 \pm 0.96 \mathrm{~d}$ on average to reach the extinction criterion, respectively.

In experiment 2 , intact rats exhibited stable responding on the active lever during the last 3 self-administration days and a gradual decrease in responding during extinction training (data not shown). All groups of rats quickly learned to respond for cocaine reinforcement and needed only a mean total of $11.00 \pm 0.33 \mathrm{~d}$ to complete the self-administration phase. Accordingly, separate ANOVAs of lever presses for the mOFC and lOFC inactivation experiments revealed only main effects of lever $\left(F_{(1,8)}=39.548\right.$, $p<0.0001 ; F_{(1,7)}=49.725, p<0.0001$, respectively) but no day main or interaction effects on responding during the last 3 selfadministration days. Thus, the rats responded more on the active than on the inactive lever, independent of self-administration day. There was no difference in cocaine intake between rats in the mOFC and lOFC inactivation experiments. The mean \pm SEM daily cocaine intake was $28.145 \pm 1.528$ infusions (17.463 \pm $0.905 \mathrm{mg} / \mathrm{kg}$ per session). During the last 3 self-administration days, all groups of rats exhibited stable responding on the active lever, with a within-subject variability of $<10 \%$ (range, $1.20-$ $3.31 \%)$. Separate overall ANOVAs for the mOFC and lOFC inactivation experiments revealed significant lever-by-day interaction effects $\left(F_{(6,42)}=5.341, p<0.0001 ; F_{(6,42)}=2.655, p<0.05\right.$, respectively) on extinction responding. Thus, active lever responding gradually decreased during the course of the extinction training. The sham intracranial infusion procedure, conducted before extinction session 4 , had no effect on responding (extinction day $4,23.88 \pm 3.41$ responses per $2 \mathrm{hr}$ ) relative to responding on the preceding extinction day (extinction day $3,27.53 \pm 2.88$ responses per $2 \mathrm{hr}$ ). Thus, the subsequent reinstatement responding on the test days did not result from the minor stress or other nonspecific factors associated with the intracranial infusion procedure. Rats needed $9.12 \pm 0.36 \mathrm{~d}$ on average to reach the extinction criterion.

Locomotor activity gradually declined across the $1 \mathrm{hr}$ test session, and none of the manipulations altered locomotor activity (data not shown). Separate ANOVAs for each experiment indicated a significant main effect of 10 min interval $(F=21.448-$ $152.000 ; p<0.0001)$ but no lesion condition or treatment main effects $(p=0.236-0.643)$ or interactions $(p=0.095-0.941$; data not shown). Thus, the observed effects of OFC manipulations on general activity cannot explain any observed differences in reinstatement of cocaine-seeking behavior (see below).

\section{Post-training infusion of Mus plus Bac into the 1OFC impairs} conditioned cue-induced reinstatement of cocaine-seeking

Response-contingent presentation of the light plus tone stimulus complex paired previously with cocaine infusions reinstated responding selectively on the active lever in control rats. The effects of $1 \mathrm{OFC}$ and $\mathrm{mOFC}$ manipulations on conditioned cue-induced reinstatement of cocaine seeking are shown in Figures 5 and 6, respectively.

Because the rate of extinction was similar across all groups (see above for number of days needed to reach extinction criterion), there was no significant difference between the groups in the length of the drug-free period that preceded the first test day. Post-training inactivation of the lOFC attenuated conditioned cue-induced cocaine-seeking behavior, whereas pretraining lesions of the lOFC and manipulations of the mOFC failed to alter this behavior (see below). The observed effects on conditioned stimulus-induced reinstatement were qualitatively different from the effects of the same OFC manipulations on locomotion (see above) and on operant responding on the inactive lever (see below). Thus, the statistically significant findings below reflect a selective impairment in conditioned cue-induced motivation for cocaine. 


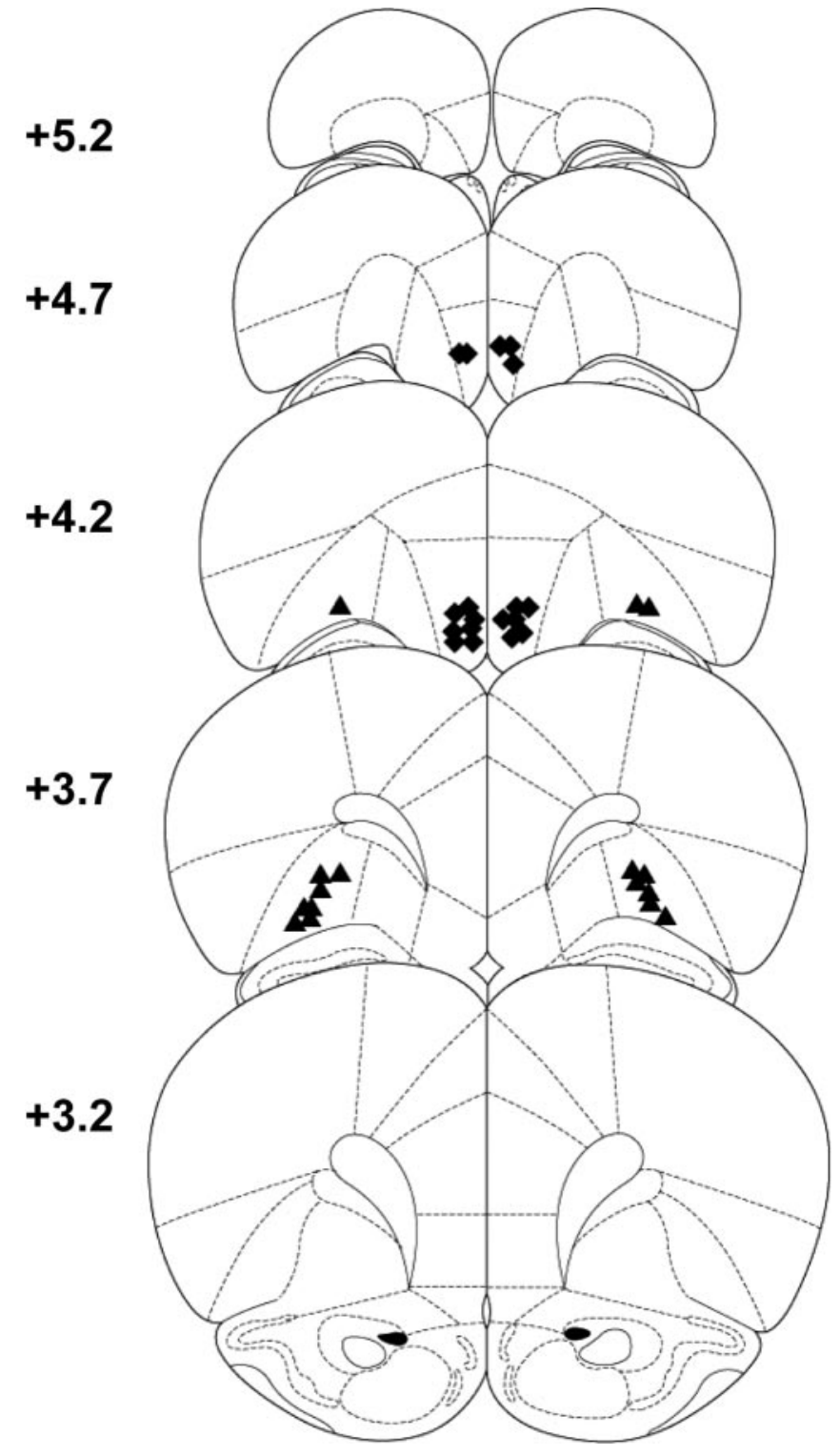

Figure 3. Schematic representation of cannula placement in Mus plus Bac inactivation experiments. Triangle and diamond symbols represent the most ventral point of the injection cannula tracks within the IOFC and $\mathrm{mOFC}$, respectively. The numbers represent the approximate distance (in millimeters) from bregma, based on the atlas of Paxinos and Watson (1997).

Pretraining lesions of the lOFC failed to alter conditioned cue-induced reinstatement of responding relative to shams (Fig. $5 A$ ). Consistent with this, the overall ANOVA of lever presses indicated a significant lever-by-test-day interaction effect $\left(F_{(1,15)}=21.835 ; p<0.0001\right)$ but no lesion condition main or interaction effects. Collapsed across lesion condition, active lever responding increased during the reinstatement test relative to the preceding extinction day (ANOVA day simple main-effect test; $\left.t_{(16)}=4.857 ; p<0.0001\right)$ and relative to responding on the inactive lever (ANOVA lever simple main-effect test; $t_{(16)}=$ $-5.544 ; p<0.0001)$. In contrast, there was no change in responding on the inactive lever across days. Planned comparisons indicated that, similarly, there was no difference in responding between the four rats that received AIC lesions (mean, 52.75) and the sham control group $\left(t_{(11)}=0.501 ; p=0.626\right)$ or the lOFC lesion group $\left(t_{(10)}=0.335 ; p=0.744\right.$; data not shown).

Post-training Mus plus Bac-induced inactivation of the lOFC impaired conditioned cue-induced reinstatement of responding relative to controls (Fig. 5B). The overall ANOVA of lever presses indicated a significant treatment by lever-by-day interaction effect $\left(F_{(1,7)}=8.048 ; p<0.05\right)$. Vehicle-pretreated rats exhibited an increase in active lever responding during the reinstatement test relative to the preceding extinction day (Tukey test; $p<$ 0.05). Mus plus Bac pretreatment attenuated the reinstatement of responding on the active lever relative to vehicle pretreatment (Tukey test; $p<0.05$ ) without altering responding on the inactive lever. An additional time-course analysis of active lever responses (Fig. 5C) revealed a treatment by $30 \mathrm{~min}$ interval interaction effect $\left(F_{(3,21)}=3.272 ; p<0.05\right)$. The source of this effect was a Mus plus Bac-induced decrease in responding, relative to vehicle, during the second and third 30 min intervals of the reinstatement test (Tukey test; $p<0.05$ ).

Pretraining lesions of the $\mathrm{mOFC}$ failed to alter conditioned cue-induced reinstatement of responding relative to shams (Fig. $6 \mathrm{~A}$ ). Consistent with this, the overall ANOVA of lever presses indicated a significant lever-by-test-day interaction effect $\left(F_{(1,13)}=15.291 ; p<0.001\right)$ but no lesion condition main or interaction effects. Collapsed across lesion condition, active lever responding increased during the reinstatement test relative to the preceding extinction day (ANOVA day simple main-effect test; $\left.t_{(14)}=-4.496 ; p<0.001\right)$ and relative to responding on the inactive lever (ANOVA lever simple main-effect test; $t_{(14)}=$ 4.929; $p<0.0001)$. In contrast, there was no change in responding on the inactive lever across days.

Post-training Mus plus Bac-induced inactivation of the mOFC failed to alter conditioned cue-induced reinstatement of responding relative to controls (Fig. 6B). The overall ANOVA of lever presses indicated a significant lever-by-day interaction effect $\left(F_{(1,8)}=26.423 ; p<0.001\right)$ but no treatment main or interaction effects. Thus, Bac plus Mus failed to alter responding relative to vehicle treatment. Collapsed across treatment, active lever responding increased during the reinstatement test relative to the preceding extinction day (ANOVA day simple main-effects test; $\left.t_{(8)}=-5.053 ; p<0.001\right)$ and relative to responding on the inactive lever (ANOVA lever simple main-effects test; $t_{(8)}=$ 6.332; $p<0.0001)$. There was no change in responding on the inactive lever across days.

\section{Opposite effects of pretraining lesions of the 1OFC versus} mOFC on cocaine-primed reinstatement of cocaine seeking Operant responding was re-extinguished after the conditioned cue-induced reinstatement test, before the cocaine-primed reinstatement test. In the lOFC lesion experiment, the number of days that elapsed between the conditioned cue-induced and cocaine-primed reinstatement test days was $4.77 \pm 0.59$ and $3.50 \pm 0.42 \mathrm{~d}$ for the sham and lesion groups, respectively. In the mOFC lesion experiment, the number of days that elapsed between the conditioned cue-induced and cocaine-primed reinstatement test days was $3.28 \pm 0.29$ and $3.87 \pm 0.35 \mathrm{~d}$ for the sham and lesion groups, respectively. In the inactivation experiment, the number of days that elapsed between the conditioned cue-induced and cocaine-primed reinstatement tests days was $2.35 \pm 0.21 \mathrm{~d}$.

After extinction, the cocaine priming injection reinstated responding selectively on the active lever (Figs. 7, 8). The effects of lOFC and mOFC manipulations on cocaine-induced reinstatement of cocaine seeking are shown in Figures 7 and 8, respectively. In experiment 1 , the lesions had no effect on cocaine self-administration, extinction, or conditioned cue-induced reinstatement of responding; therefore, lesion and sham control groups had identical 
behavioral history up until the cocaineprimed reinstatement test. In experiment 2, rats were tested using a fully counterbalanced within-subjects design, which resulted in all rats having identical behavioral history up until the cocaine-primed reinstatement test. Therefore, the effects of the lesion and inactivation manipulations on cocaine-induced reinstatement of cocaine seeking cannot be attributed to pre-existing differences between the experimental and respective control groups. Cocaine-primed reinstatement of responding was not caused by the stress of intraperitoneal drug administration, because intraperitoneal administration of saline alone or in combination with intracranial administration of saline fails to reinstate responding (Neisewander et al., 2000; Fuchs and See, 2002; Fuchs et al., 2002; Ledford et al., 2003). In addition, the effects of lOFC inactivation on stress-induced reinstatement of cocaine-seeking behavior (i.e., impairment) (Capriles et al., 2003) and the effects of OFC manipulations on measures of general activity, including locomotion (see above) and inactive lever responding (see below), were inconsistent with the observed differences in reinstatement of cocaine-seeking behavior (see below). Thus, the following statistically significant findings reflect selective effects on pharmacologically induced motivation for cocaine.

Pretraining lesions of the lOFC potentiated cocaine-induced reinstatement of responding relative to shams (Fig. $7 A$ ). Consistent with this, the overall ANOVA indicated a significant lesion condition by lever-by-day interaction effect $\left(F_{(1,15)}=\right.$ 4.93; $p<0.05)$. Both the sham and lOFC lesion groups exhibited an increase in active lever responding during the reinstatement test relative to the preceding extinction day (Tukey test; $p<0.05$ ) and relative to responding on the inactive lever (Tukey test; $p<0.05$ ). Moreover, the lOFC lesion group exhibited a significantly greater increase in responding on the active lever during the reinstatement test relative to the sham control group (Tukey test; $p<0.05$ ). Additional time-course analysis of active lever responding (Fig. $7 B$ ) revealed that the lOFC lesion and sham control groups exhibited different patterns of responding. Active lever responding declined after the first 30 min interval in the sham control group $\left(F_{(3,24)}=33.950 ; p<\right.$ 0.0001; Tukey tests, $p<0.05)$, whereas responding did not change across the four $30 \mathrm{~min}$ intervals of the $2 \mathrm{hr}$ session in the lOFC lesion group $\left(F_{(3,21)}=0.283 ; p=0.837\right)$. There was no change in responding on the inactive lever across days, and there was no difference between the groups in responding on the inactive lever. Furthermore, planned comparisons indicated that there was no difference in responding between the four rats that received AIC lesions (mean, 73.25) versus the sham control group $\left(t_{(11)}=1.183 ; p=0.262\right)$ or the lOFC lesion group $\left(t_{(10)}=\right.$ $0.905 ; p=0.387$; data not shown).

Post-training Mus plus Bac-induced inactivation of the lOFC failed to alter cocaine-induced reinstatement of responding relative to controls (Fig. 7C). The overall ANOVA indicated a signif8; $\mathrm{mOFC}$ sham, $n=7$.

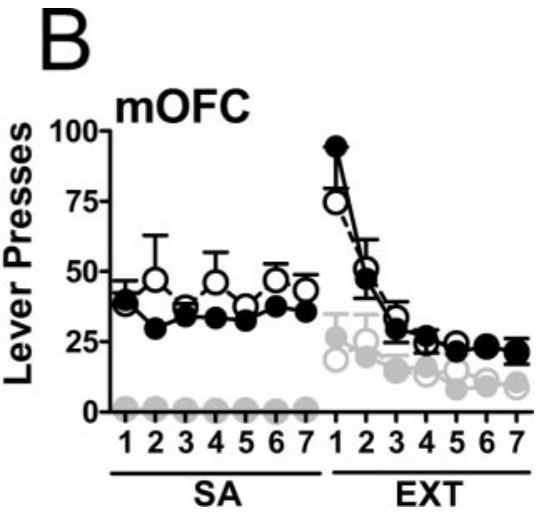

Figure 4. Effects of pretraining lesions of the $\operatorname{lOFC}(A)$ and $\mathrm{mOFC}(B)$ on active and inactive lever responses (mean \pm SEM) responses resulted in the delivery of a cocaine infusion and simultaneous presentation of a light-tone stimulus complex. During
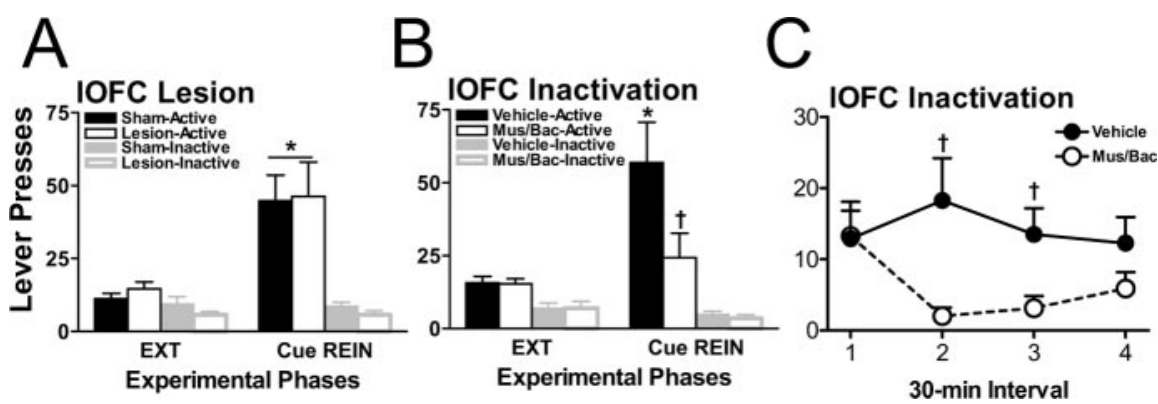

Figure 5. Effects of pretraining lesions $(A)$ and post-training Mus plus Bac-induced inactivation $(B, C)$ of the IOFC on condiactive lever resulted in presentations of the light-tone stimulus complex in the significant difference in responding relative to the vehicle-pretreated group (Tukey test; $p<0.05$ ). Sample sizes: I0FClesion, $n=$ $8 ; 10 F C$ sham, $n=9 ; 10 F C$ inactivation, $n=8$.
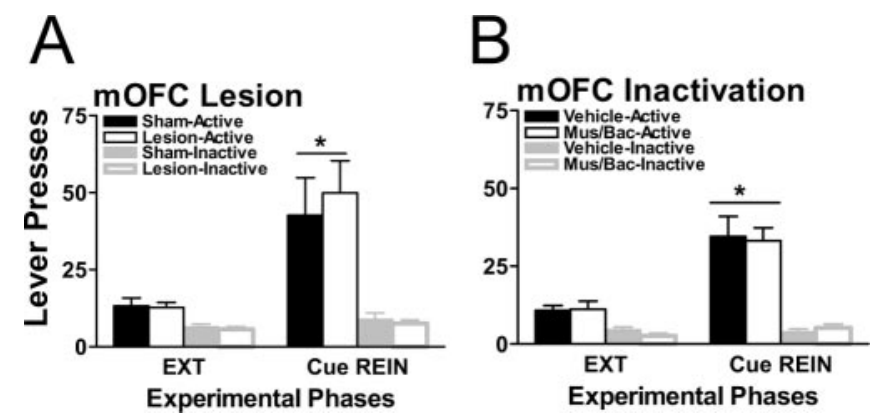

Figure 6. Effects of pretraining lesions $(A)$ and post-training Mus plus Bac-induced inactivation $(B)$ of the mOFC on conditioned cue-induced reinstatement (Cue REIN) of extinguished (EXT) cocaine-seeking behavior. Asterisks represent a significant difference relative to responding on the preceding extinction day and relative to the inactive lever (ANOVA simple main effect test; $p<0.05$ ). Sample sizes: $\mathrm{m} 0 \mathrm{FC}$ lesion, $n=8 ; \mathrm{m0FC}$ sham, $n=7 ; \mathrm{m0FC}$ inactivation, $n=9$.

icant lever-by-day interaction effect $\left(F_{(1,7)}=24.126 ; p<0.005\right)$ but no treatment main or interaction effects. Thus, Mus plus Bac pretreatment failed to alter responding relative to vehicle pretreatment. Collapsed across pretreatment, active lever responding increased during the reinstatement test relative to the preceding extinction day (ANOVA day simple main-effects test; $t_{(7)}=$ $-4.645 ; p<0.005)$ and relative to responding on the inactive 
A



B
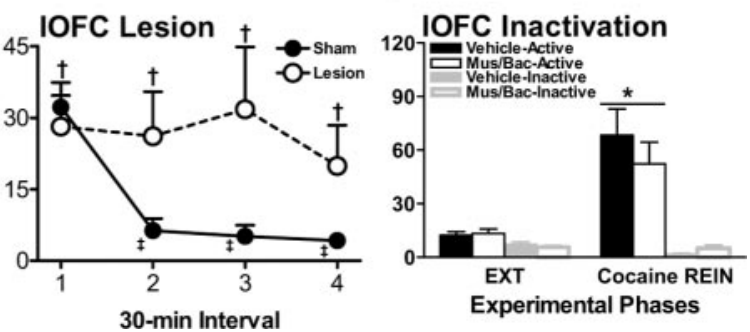

Figure 7. Effects of pretraining lesions $(A, B)$ and post-training Mus plus Bac-induced inactivation ( $C$ ) of the IOFC on cocaineinduced reinstatement (Cocaine REIN) of extinguished (EXT) cocaine-seeking behavior. On the cocaine reinstatement test day, rats received an intraperitoneal cocaine priming injection immediately before placement into the chambers; responses had no programmed consequences. Asterisks represent a significant difference relative to responding on the preceding extinction day and relative to the inactive lever $(A$, Tukey test, $p<0.05 ;$; , ANOVA simple main effect test, $p<0.05)$. Daggers represent a significant difference in responding relative to the sham control group ( $A$, Tukey test, $p<0.05 ; B$, lesion condition main effect, $p<0.05$ ). Double daggers represent a significant difference in responding relative to the first 30 min interval (Tukey test; $p<0.05$ ). Sample sizes: IOFC lesion, $n=8$; IOFC sham, $n=9$; IOFC inactivation, $n=8$.
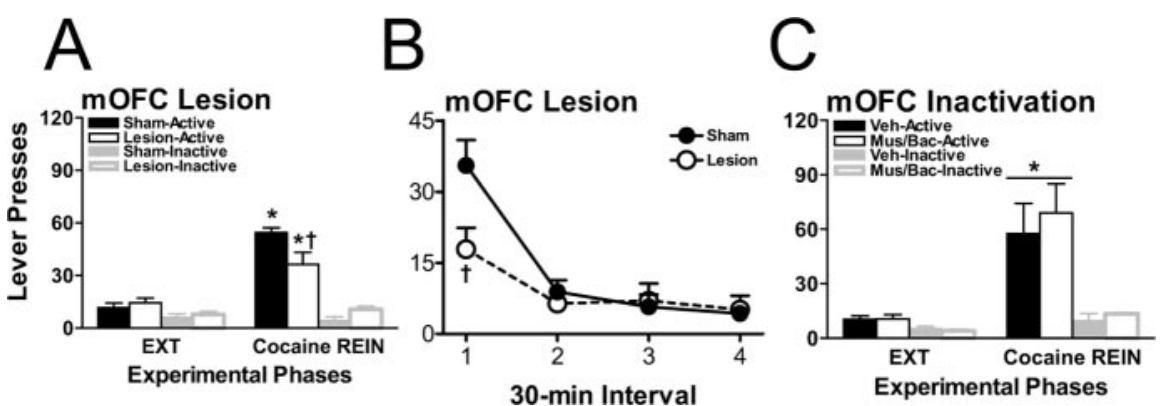

Figure 8. Effects of pretraining lesions $(A, B)$ and post-training Mus plus Bac-induced inactivation ( $C$ ) of the m0FC on cocaineinduced reinstatement (Cocaine REIN) of extinguished (EXT) cocaine-seeking behavior. Asterisks represent a significant difference relative to responding on the preceding extinction day and relative to the inactive lever $(A$, Tukey test, $p<0.05 ; C$, ANOVA simple main effect test, $p<0.05$ ). Daggers represent a significant difference in responding relative to the sham control group (Tukey test; $p<0.05$ ). Sample sizes: m0FC lesion, $n=8 ; \operatorname{m0FC~sham,~} n=7 ; \operatorname{m0FC}$ inactivation, $n=9$.

lever (ANOVA lever simple main-effects test; $t_{(7)}=5.238 ; p<$ $0.001)$. In contrast, there was no change in responding on the inactive lever across days.

Pretraining lesions of the mOFC impaired cocaine-induced reinstatement of responding relative to shams (Fig. $8 \mathrm{~A}$ ). The overall ANOVA indicated a significant lesion condition by leverby-day interaction effect $\left(F_{(1,13)}=9.432 ; p<0.01\right)$. Both sham and $\mathrm{mOFC}$ lesion groups exhibited an increase in active lever responding during the reinstatement test relative to the preceding extinction day (Tukey test; $p<0.05$ ) and relative to responding on the inactive lever (Tukey test; $p<0.05$ ). However, the mOFC lesion group exhibited significantly less responding on the active lever on the cocaine reinstatement test day relative to the sham control group (Tukey test; $p<0.05$ ). There was no change in responding on the inactive lever across days, and there was no difference between the groups in responding on the inactive lever. Additional time-course analysis of active lever responding revealed a lesion condition by time interaction effect $\left(F_{(3,39)}=3.239 ; p<0.05\right)$, indicating that the lesion effect was limited to the first $30 \mathrm{~min}$ of testing (Tukey test; $p<0.05$ ) (Fig. $8 B$ ).

Post-training Mus plus Bac-induced inactivation of the mOFC failed to alter cocaine-induced reinstatement of responding relative to controls (Fig. $8 \mathrm{C}$ ). The overall ANOVA indicated a significant lever-by-day interaction effect $\left(F_{(1,8)}=16.755 ; p<\right.$ 0.005 ) but no treatment main or interaction effects. Thus, Mus plus Bac pretreatment failed to alter responding relative to vehi- cle. Collapsed across pretreatment, active lever responding increased during the reinstatement test relative to the preceding extinction day (ANOVA simple maineffects test; $\left.t_{(8)}=-4.075 ; p<0.005\right)$ and relative to responding on the inactive lever (ANOVA simple main-effects test; $t_{(8)}=$ $4.430 ; p<0.005)$. In contrast, there was no change in responding on the inactive lever across days.

\section{Discussion}

The findings from the present study underscore the unique role of the $\mathrm{OFC}$ in drug seeking. Post-training $\mathrm{lOFC}$ inactivation inhibited cue-induced reinstatement of cocaine seeking, whereas pretraining lOFC lesions and mOFC manipulations failed to alter this reinstatement. In contrast, lOFC lesions augmented, mOFC lesions attenuated, and lOFC or mOFC inactivation failed to alter cocaine-primed reinstatement. These findings also highlight the functional heterogeneity of the rat OFC, which has been mostly neglected by preclinical research, although such heterogeneity is clearly evident in humans (Elliott et al., 2000; Arana et al., 2003).

\section{Involvement of the OFC in cue-induced} reinstatement of cocaine seeking

During chronic drug use, drug-paired stimuli acquire incentive motivationalconditioned reinforcing effects that enable them to reinstate drug-seeking behavior (Stewart, 1983). Specifically, conditioned cue-induced reinstatement relies on the learning of stimulus-reward associations during self-administration training and the recall and utilization of this information during reinstatement testing. In the present study, post-training inactivation of the lOFC but not the mOFC blocked cue-induced reinstatement. Similar to lOFC inactivation, complete OFC lesions elicit retroactive deficits in discriminated approach, a task also based on stimulus-reward associations (Chudasama and Robbins, 2003). The functional heterogeneity observed in the present study is likely related to the differential connectivity of the lOFC and mOFC. The lOFC has more extensive connections with elements of the corticolimbic circuitry that mediates conditioned cue-induced cocaine seeking, including the dmPFC, BLA, NACcore, and VTA (Meil and See, 1997; Cavada et al., 2000; Ledford et al., 2003; McLaughlin and See, 2003; Fuchs et al., 2004), relative to the mOFC. Conversely, the mOFC has dense connections with the hippocampal formation, a structure that does not appear to play an important role in cue-induced reinstatement, although it is widely implicated in associative learning and memory (Black et al., 2004; our unpublished observations) (but see Sun and Rebec, 2003). The present findings suggest that the functional integrity of the lOFC is necessary for the storage, retrieval, or utilization of information about the motivational significance of cocaine-paired stimuli and consequently conditioned cue-induced reinstatement of cocaine seeking as long as the lOFC is intact at the time of stimulusreward learning. Conversely, the mOFC does not appear to play 
an important role in conditioned cue-induced cocaine-seeking behavior.

Unlike post-training inactivation, lOFC lesions before selfadministration training failed to impair cue-induced cocaine seeking. A number of possibilities may explain this discrepancy. First, the functional integrity of the lOFC may not be necessary for the learning and utilization of stimulus-reward associations that underlie cue-induced reinstatement if these associations form after lOFC lesion. This also implies that activity in the remaining elements of the relapse circuitry is sufficient for drugpaired cues to acquire and maintain motivational significance and elicit cue-controlled behavior independent of lOFC input. Thus, the lOFC plays a more circumscribed role in conditioned cue-induced reinstatement relative to the BLA, because the functional integrity of the BLA is necessary for conditioned cueinduced reinstatement regardless of whether stimulus-reward learning occurs before or after BLA insult (Kruzich and See, 2001). Second, the differential mechanisms of action of lOFC lesions versus inactivation may account for the discrepancy between the effects of these manipulations on reinstatement responding. Both manipulations likely attenuate glutamate output from the lOFC. In addition, however, excitotoxic lesions also disrupt GABA neurotransmission and alter somatostatin, neuropeptide $\mathrm{Y}$, substance $\mathrm{P}$, cholecystokinin, and choline acetyltransferase immunoreactivity (Beal et al., 1991; Ferrante et al., 1993). Furthermore, Mus plus Bac facilitates GABA neurotransmission and alters the release of various neurotransmitters, including dopamine, in the brain (Matsumoto et al., 2003). Third, compensatory neuroadaptation may occur after prolonged cell loss but not acute loss of function and may result in a recovery of function. Thus, importantly, permanent excitotoxic lesions versus temporary GABA agonist-induced inactivation are not equivalent approaches, and future studies will need to investigate the mechanisms for the acute and protracted effects of these manipulations.

Cocaine-induced OFC damage (Franklin et al., 2002; Matochik et al., 2003) likely develops after the stimuli most directly related to cocaine use are associated with cocaine (i.e., posttraining). In rats, post-training lOFC inactivation attenuated cue-induced reinstatement. This implies that, in addicts, cocaine-induced global lOFC damage should attenuate the propensity for cue-induced drug relapse. However, cocaine users exhibit enhanced activation of the OFC (Bonson et al., 2002) and craving with exposure to basic cocaine-associated cues (i.e., paraphernalia). Although it is unclear whether OFC damage uniformly involves all neuronal subtypes, one possible explanation that reconciles these seemingly inconsistent findings is that a disproportional loss of inhibitory interneurons within the OFC may underlie the strong cue reactivity in cocaine addicts. Furthermore, prolonged cocaine-induced cell loss within the OFC may elicit compensatory neuroadaptations.

\section{Involvement of the OFC in cocaine-induced reinstatement of cocaine seeking}

Similar to drug-paired stimuli, small amounts of cocaine can enhance drug craving after prolonged abstinence and initiate or prolong a cocaine binge (Jaffe et al., 1989). The incentive motivational effects of cocaine are postulated to mediate these effects as well as cocaine-primed reinstatement (Stewart, 1983). In the present study, lOFC lesions greatly potentiated cocaine-induced reinstatement, whereas mOFC lesions slightly attenuated this reinstatement. Control rats exhibited peak responding during the first $30 \mathrm{~min}$ after cocaine priming. Their responding then gradu- ally extinguished, likely because they detected that cocaine reinforcement was not available. In contrast, lOFC lesion rats responded at a constant rate throughout the $2 \mathrm{hr}$ session. This finding likely reflects a lesion-induced impairment to suppress the previously reinforced response when it is no longer adaptive (Iversen and Mishkin, 1970; Jones and Mishkin, 1972; Elliott et al., 2000; Arana et al., 2003). A similar OFC lesion-induced perseverative error has been noted for classical conditioned behaviors that rely primarily on stimulus-reward associations (Gaffan et al., 1993; Gallagher et al., 1999; Chudasama and Robbins, 2003; Pickens et al., 2003). However, to our knowledge, it has not been reported for instrumental behaviors. Importantly, this finding further refines our understanding of the neurocircuitry of cocaine-induced drug seeking. Previously identified elements of this circuitry include the VTA, dmPFC, NACcore, and ventral pallidum (McFarland and Kalivas, 2001), each of which possesses more extensive direct or indirect connections with the lOFC than the mOFC, as described above. Because these nuclei comprise a quasi-motor circuitry, cocaine-induced drug seeking was postulated to be an "automatic" behavior. Contrary to this hypothesis, the perseverative error in IOFC lesion rats implies that the OFC normally suppresses cocaine-primed drug seeking, allowing for cortically mediated cognitive control over this behavior (Jentsch and Taylor, 1999). The behavioral profile after mOFC lesions was distinctly different from that seen after lOFC lesions. The mOFC lesions attenuated cocaine-induced reinstatement of drug seeking. Given its modest size, this may be a spurious effect; however, it is consistent with the ascribed role of the mOFC in monitoring the motivational significance of, and in responding to, stimuli (Arana et al., 2003).

Interestingly, only permanent OFC lesions, as opposed to temporary inactivation, altered cocaine-primed drug seeking. This suggests that perhaps the increased behavioral influence of structures that normally facilitate drug seeking does not manifest itself after short-term functional impairment within the lOFC. Consistent with the idea that long-term cell loss is necessary for functional impairment, the lesion groups themselves were not impaired in monitoring the motivational effects of cocaine earlier during the experiment (i.e., during self-administration and extinction). Alternatively, the discrepant effects of lesions versus neuronal inactivation may be attributable to differences between the mechanisms of action of these two fiber-sparing manipulations, as discussed above. NMDA lesions also permanently eliminate neural output from the OFC. Conversely, high-dose Mus plus Bac administration inactivates the OFC by hyperpolarizing neurons. It is unlikely, however, that the intact cocaine-induced reinstatement observed after Mus plus Bac pretreatment was a result of altered or residual electrophysiological activity, because a similar lack of effect on cocaine-induced reinstatement is observed when the sodium channel blocker tetrodotoxin is used to eliminate neural impulses within the lOFC more similar to lesions (Capriles et al., 2003). Future studies will need to evaluate these alternate hypotheses by examining the effects of OFC lesions on cocaine-induced reinstatement after a short postlesion interval and by determining critical differences in the mechanisms of action of excitotoxic lesions versus inactivation techniques.

\section{The role of the OFC in cognitive function associated with drug relapse}

The rat OFC is functionally heterogeneous with respect to drugseeking behavior. The mOFC does not play a critical role in conditioned cue-induced reinstatement of cocaine seeking, whereas 
the lOFC is involved in the long-term storage, retrieval, or utilization of stimulus-reward associations, which underlie the initiation of cue-induced drug seeking if these associations are established while the lOFC is intact. lOFC lesions elicit perseveration in cocaine seeking after cocaine priming, whereas mOFC lesions impair this behavior. Overall, these findings suggest that the OFC regulates aspects of the incentive motivational effects of cocaine and cocaineassociated stimuli, and that lOFC damage, cocaine-induced or otherwise, may enhance the propensity for cocaine-induced relapse in cocaine users. The impairments observed in rats are similar to those reported in primates and humans with OFC damage, suggesting that the rat model is useful for exploring the neural bases of putative frontal cortical deficits relevant to drug addiction.

\section{References}

Alleweireldt AT, Kirschner KF, Blake CB, Neisewander JL (2003) D1receptor drugs and cocaine-seeking behavior: investigation of receptor mediation and behavioral disruption in rats. Psychopharmacology (Berl) 168:109-117.

Amaral DG, Price JL, Pitkanen A, Carmichael ST (1992) Anatomical organization of the primate amygdaloid complex. In: The amygdala: neurobiological aspects of emotion, memory, and mental dysfunction (Aggleton JP, ed), pp 1-66. New York: Wiley.

Arana FS, Parkinson JA, Hinton E, Holland AJ, Owen AM, Roberts AC (2003) Dissociable contributions of the human amygdala and orbitofrontal cortex to incentive motivation and goal selection. J Neurosci 23:9632-9638.

Baker DA, Tran-Nguyen TL, Fuchs RA, Neisewander JL (2001) Influence of individual differences and chronic fluoxetine treatment on cocaineseeking behavior in rats. Psychopharmacology (Berl) 155:18-26.

Beal MF, Swartz KJ, Finn SF, Mazurek MF, Kowall NW (1991) Neurochemical characterization of excitotoxin lesions in the cerebral cortex. J Neurosci 11:147-158.

Bechara A, Damasio AR, Damasio H, Anderson SW (1994) Insensitivity to future consequences following damage to human prefrontal cortex. Cognition 50:7-15.

Black YD, Green-Jordan K, Eichenbaum HB, Kantak KM (2004) Hippocampal memory system function and the regulation of cocaine selfadministration behavior in rats. Behav Brain Res 151:225-238.

Bolla KI, Eldreth DA, London ED, Kiehl KA, Mouratidis M, Contoreggi C, Matochik JA, Kurian V, Cadet JL, Kimes AS, Funderburk FR, Ernst M (2003) Orbitofrontal cortex dysfunction in abstinent cocaine abusers performing a decision-making task. NeuroImage 19:1085-1094.

Bonson KR, Grant S, Contoreggi C, Links J, Metalfe J, Weyl LH, Kurian V, Ernst M, London ED (2002) Neural systems and cue-induced cocaine craving. Neuropsychopharmacology 26:376-386.

Burmeister JJ, Lungren EM, Kirschner KF, Neisewander JL (2004) Differential roles of 5-HT receptor subtypes in cue and cocaine reinstatement of cocaineseeking behavior in rats. Neuropsychopharmacology 29:660-668.

Butter CM (1969) Perseveration in extinction and in discrimination reversal tasks following selective frontal ablations in Macaca mulatta. Physiol Behav 4:163-171.

Capriles N, Rodaros D, Sorge RE, Stewart J (2003) A role for the prefrontal cortex in stress- and cocaine-induced reinstatement of cocaine seeking in rats. Psychopharmacology (Berl) 168:66-74.

Carmichael ST, Price JL (1995) Limbic connections of the orbital and medial prefrontal cortex in macaque monkeys. J Comp Neurol 363:615-641.

Cavada C, Company T, Tejedor J, Cruz-Rizzolo RJ, Reinoso-Suarez F (2000) The anatomical connections of the macaque monkey orbitofrontal cortex. A review. Cereb Cortex 10:220-242.

Chudasama Y, Robbins TW (2003) Dissociable contributions of the orbitofrontal and infralimbic cortex to pavlovian autoshaping and discrimination reversal learning: further evidence for the functional heterogeneity of the rodent frontal cortex. J Neurosci 23:8771-8780.

de Bruin JP, van Oyen HG, Van de Poll N (1983) Behavioural changes following lesions of the orbital prefrontal cortex in male rats. Behav Brain Res 10:209-232.

Elliott R, Dolan RJ, Frith CD (2000) Dissociable functions in the medial and lateral orbitofrontal cortex: evidence from human neuroimaging studies. Cereb Cortex 10:308-317.
Ferrante RJ, Kowall NW, Cipolloni PB, Storey E, Beal MF (1993) Excitotoxin lesions in primates as a model for Huntington's disease: histopathologic and neurochemical characterization. Exp Neurol 119:46-71.

Franklin TR, Acton PD, Maldjian JA, Gray JD, Croft JR, Dackis CA, O’Brien CP, Childress AR (2002) Decreased gray matter concentration in the insular, orbitofrontal, cingulate, and temporal cortices of cocaine patients. Biol Psychiatry 51:134-142.

Fuchs R, Tran-Nguyen L, Weber S, Khroyan T, Neisewander J (2002) Effects of 7-OH-DPAT on cocaine-seeking behavior and on re-establishment of cocaine self-administration. Pharmacol Biochem Behav 72:623-632.

Fuchs RA, See RE (2002) Basolateral amygdala inactivation abolishes conditioned stimulus- and heroin-induced reinstatement of extinguished heroinseeking behavior in rats. Psychopharmacology (Berl) 160:425-433.

Fuchs RA, Evans KL, Parker MC, See RE (2004) Differential involvement of the core and shell subregions of the nucleus accumbens in conditioned cue-induced reinstatement of cocaine seeking in rats. Psychopharmacology (Berl), in press.

Gaffan D, Murray EA, Fabre-Thorpe M (1993) Interaction of the amygdala with the frontal lobe in reward memory. Eur J Neurosci 5:968-975.

Gallagher M, McMahan RW, Schoenbaum G (1999) Orbitofrontal cortex and representation of incentive value in associative learning. J Neurosci 19:6610-6614.

Gottfried JA, O’Doherty J, Dolan RJ (2003) Encoding predictive reward value in human amygdala and orbitofrontal cortex. Science 301:1104-1107.

Grimm JW, See RE (2000) Dissociation of primary and secondary rewardrelevant limbic nuclei in an animal model of relapse. Neuropsychopharmacology 22:473-479.

Haber SN, Kunishio K, Mizobuchi M, Lynd-Balta E (1995) The orbital and medial prefrontal circuit through the primate basal ganglia. J Neurosci 15:4851-4867.

Hutcheson DM, Everitt BJ (2003) The effects of selective orbitofrontal cortex lesions on the acquisition and performance of cue-controlled cocaine seeking in rats. Ann NY Acad Sci 1003:410-411.

Iversen S, Mishkin M (1970) Perseverative interference in monkey following selective lesions of the inferior prefrontal convexity. Exp Brain Res $11: 376-386$.

Jaffe JH, Cascella NG, Kumor KM, Sherer MA (1989) Cocaine-induced cocaine craving. Psychopharmacology (Berl) 97:59-64.

Jentsch JD, Taylor JR (1999) Impulsivity resulting from frontostriatal dysfunction in drug abuse: implications for the control of behavior by reward-related stimuli. Psychopharmacology (Berl) 146:373-390.

Jentsch JD, Olausson P, De La Garza R-II, Taylor JR (2002) Impairments of reversal learning and response perseveration after repeated, intermittent cocaine administrations to monkeys. Neuropsychopharmacology 26:183-190.

Jones B, Mishkin M (1972) Limbic lesions and the problem of stimulusreinforcement associations. Exp Neurol 36:362-377.

Kowalska DM, Bachevalier J, Mishkin M (1991) The role of the inferior prefrontal convexity in performance of delayed nonmatching to sample. Neuropsychologia 29:583-600.

Kruzich PJ, See RE (2001) Differential contributions of the basolateral and central amygdala in the acquisition and expression of conditioned relapse to cocaine-seeking behavior. J Neurosci 21:RC155(1-5).

Kruzich PJ, Grimm JW, Rustay NR, Parks CD, See RE (1999) Predicting relapse to cocaine-seeking behavior: a multiple regression approach. Behav Pharmacol 10:513-521.

Ledford CC, Fuchs RA, See RE (2003) Potentiated reinstatement of cocaineseeking behavior following $\mathrm{D}$-amphetamine infusion into the basolateral amygdala. Neuropsychopharmacology 28:1721-1729.

London ED, Ernst M, Grant S, Bonson K, Weinstein A (2000) Orbitofrontal cortex and human drug abuse: functional imaging. Cereb Cortex 10:334-342.

Matochik JA, London ED, Eldreth DA, Cadet JL, Bolla KI (2003) Fronta cortical tissue composition in abstinent cocaine abusers: a magnetic resonance imaging study. NeuroImage 19:1095-1102.

Matsumoto M, Kanno M, Togashi H, Ueno K, Otani H, Mano Y, Yoshioka M (2003) Involvement of $\mathrm{GABA}_{\mathrm{A}}$ receptors in the regulation of the prefrontal cortex on dopamine release in the rat dorsolateral striatum. Eur J Pharmacol 482:177-184.

McFarland K, Kalivas PW (2001) The circuitry mediating cocaine-induced reinstatement of drug-seeking behavior. J Neurosci 21:8655-8663. 
McLaughlin J, See RE (2003) Selective inactivation of the dorsomedial prefrontal cortex and the basolateral amygdala attenuates conditioned-cued reinstatement of extinguished cocaine-seeking behavior in rats. Psychopharmacology (Berl) 168:57-65.

Meil WM, See RE (1997) Lesions of the basolateral amygdala abolish the ability of drug associated cues to reinstate responding during withdrawal from self-administered cocaine. Behav Brain Res 87:139-148.

Morecraft RJ, Geula C, Mesulam MM (1992) Cytoarchitecture and neural afferents of orbitofrontal cortex in the brain of the monkey. J Comp Neurol 323:341-358.

Neisewander JL, Baker DA, Fuchs RA, Tran-Nguyen LT, Palmer A, Marshall JF (2000) Fos protein expression and cocaine-seeking behavior in rats after exposure to a cocaine self-administration environment. J Neurosci 20:798-805.

Nobre AC, Coull JT, Frith CD, Mesulam MM (1999) Orbitofrontal cortex is activated during breaches of expectation in tasks of visual attention. Nat Neurosci 2:11-12.

O’Malley SS, Adamse M, Heaton RK, Gawin FH (1992) Neuropsychological impairments in chronic cocaine abusers. Am J Drug Alcohol Abuse 18:131-144.

Ongur D, Price JL (2000) The organization of networks within the orbital and medial prefrontal cortex of rats, monkeys and humans. Cereb Cortex 10:206-219.

Paxinos G, Watson C (1997) The rat brain in stereotaxic coordinates, Ed 3. Los Angeles: Academic.

Pears A, Parkinson JA, Hopewell L, Everitt BJ, Roberts AC (2003) Lesions of the orbitofrontal but not medial prefrontal cortex disrupt conditioned reinforcement in primates. J Neurosci 23:11189-11201.

Pickens CL, Saddoris MP, Setlow B, Gallagher M, Holland P, Schoenbaum G (2003) Differential roles for orbitofrontal cortex and basolateral amygdala in a reinforcer devaluation task. J Neurosci 23:11078-11084.

Schoenbaum G, Ramus SJ, Shaham Y, Saddoris MP, Setlow B (2003) Prior cocaine exposure causes deficits in the acquisition of odor-guided discriminations and reversals similar to orbitofrontal cortex lesions. Soc Neurosci Abstr 29:716.5.

Stewart J (1983) Conditioned and unconditioned drug effects in relapse to opiate and stimulant drug self-administration. Prog Neuropsychopharmacol Biol Psychiatry 7:591-597.

Sun WL, Rebec GU (2003) Lidocaine inactivation of ventral subiculum attenuates cocaine-seeking behavior in rats. J Neurosci 23:10258-10264.

Tran-Nguyen LT, Fuchs RA, Coffey GP, Baker DA, O'Dell LE, Neisewander JL (1998) Time-dependent changes in cocaine-seeking behavior and extracellular dopamine levels in the amygdala during cocaine withdrawal. Neuropsychopharmacology 19:48-59.

Vogt BA, Pandya DN (1987) Cingulate cortex of the rhesus monkey. II Cortical afferents. J Comp Neurol 262:271-289.

Volkow ND, Fowler JS (2000) Addiction, a disease of compulsion and drive: involvement of the orbitofrontal cortex. Cereb Cortex 10:318-325.

Wang GJ, Volkow ND, Fowler JS, Cervany P, Hitzemann RJ, Pappas NR, Wong CT, Felder C (1999) Regional brain metabolic activation during craving elicited by recall of previous drug experiences. Life Sci 64:775-784. 